\title{
Influence of Retrogression and Reaging Treatment on Microstructure and Microhardness of the 3A21/7075 Aluminum Alloy Cladding Material
}

\author{
Ming Hu $\mathbb{D}^{1},{ }^{1,2}$ Xiaoxue Ren $\mathbb{D}^{\mathbb{D}},{ }^{1}$ Jianbo Sun $\mathbb{D}^{\mathbb{D}},{ }^{1,2}$ and Yunlong Zhang $\mathbb{D}^{1,2}$ \\ ${ }^{1}$ College of Materials Science and Engineering, Jiamusi University, Jiamusi, 154007 Heilongiiang, China \\ ${ }^{2}$ Department of Education Metal Wear-Resistant Materials and Surface Technology Engineering Research Center, Jiamusi, \\ 154007 Heilongjiang, China
}

Correspondence should be addressed to Jianbo Sun; 920340063@qq.com and Yunlong Zhang; ylzhdr@126.com

Received 11 October 2020; Revised 19 January 2021; Accepted 20 February 2021; Published 10 March 2021

Academic Editor: Xuelong Hao

Copyright ( 92021 Ming Hu et al. This is an open access article distributed under the Creative Commons Attribution License, which permits unrestricted use, distribution, and reproduction in any medium, provided the original work is properly cited.

\begin{abstract}
The 7075 aluminum alloy was an important structural material in the field of aeronautics and astronautics. With the development of this field, the requirements for its comprehensive properties were increasing. A novel casting method, the impact jet solid-liquid compound casting, was adopted to fabricate the 3A21/7075 aluminum alloy cladding material. Retrogression and reaging (RRA) treatment was further applied to the 3A21/7075 aluminum alloy cladding material in order to investigate the influence of RRA on microstructure and microhardness of the 3A21/7075 aluminum alloy cladding material. Then, the electron backscattered diffraction (EBSD) technique and the transmission electron microscope (TEM) together with the energy dispersive spectrometer (EDS) and the hardness test were utilized to analyze the influence of RRA treatment on microstructure and hardness of the 3A21/7075 aluminum alloy cladding material. The research results showed the 3A21/7075 aluminum alloy cladding material had better deformability. The amount of fine and dispersed phases precipitated in grains was in favor of improving the comprehensive mechanical properties of the 3A21/7075 aluminum alloy cladding material. This research might provide data and a theoretical approach for the engineering application of the 3A21/7075 aluminum alloy cladding material.
\end{abstract}

\section{Introduction}

High-strength aluminum alloy had been exploited as a mold material for prototype, production, and blow molding applications, due to the high thermal conductivity and the convenience of machinability [1]. For example, the 7075 aluminum alloy was a typical representative and $\mathrm{Al}-\mathrm{Zn}-\mathrm{Mg}-\mathrm{Cu}$ was the reinforcement. The aluminum alloy contained $1 \% \sim 8 \% \mathrm{Zn}$ and a small amount of $\mathrm{Mg}, \mathrm{Cr}$, or $\mathrm{Cu}$, which was a heattreatable strengthened aluminum alloy [2]. After quenching and aging, a large number of dispersive hardening phases were precipitated to strengthen the alloy. In the 1940s, the 7075-T6 alloys with high-strength properties were developed and subsequently used in aerospace fields such as military aircraft. T6 treatment was the most basic heat treatment system and can achieve high strength, but it was more prone to SCC tendencies [3]. At present, the processing technology of rolling aluminum alloy with wide and thick plates was still a bottleneck problem [4]. Currently, materials capable of producing thick aluminum alloy plates include Alcoa, Alcan (Ravenswood rolling Plant in the United States, Isuval rolling Plant in France), the Kaiser aluminum and chemical companies in the United States (Trey wood rolling factory), Alex company (Koblenz rolling factory), and Russian aluminum company in Myanmar (Kamensk Uralsky Metallurgical Plant). The HOKOTOL alloy produced by Corus Aluminum Wlzpodukte was a kind of high-strength aluminum alloy, mainly applied for thick plates of aluminum alloy, and its thickness can reach $700 \mathrm{~mm}$. Mic-6 aluminum alloy belongs to precision casting aluminum heavy plate die alloy, and its typical thickness can reach $6 \sim 100 \mathrm{~mm}$. The application of this product can replace the hot-rolled plate of ingot casting, and it can reduce the manufacturing cost of the die. The composition of the alloy was still under wraps. At present, only a 
TABLE 1: Chemical composition of the 7075 and the 3A21 (mass fraction, \%).

\begin{tabular}{lcccccccccc}
\hline Material & $\mathrm{Si}$ & $\mathrm{Fe}$ & $\mathrm{Cu}$ & $\mathrm{Mn}$ & $\mathrm{Mg}$ & $\mathrm{Cr}$ & $\mathrm{Zn}$ & $\mathrm{Ti}$ & $\mathrm{Other}$ & $\mathrm{Al}$ \\
\hline 7075 & 0.4 & 0.5 & $1.2 \sim 2.0$ & 0.3 & $2.1 \sim 2.9$ & $0.18 \sim 0.28$ & $5.1 \sim 6.1$ & 0.20 & 0.20 & $\mathrm{Bal}$. \\
$3 \mathrm{~A} 21$ & 0.6 & 0.7 & 0.2 & $1.0 \sim 1.6$ & 0.05 & - & 0.1 & 0.15 & 0.15 & $\mathrm{Bal}$. \\
\hline
\end{tabular}

few companies can produce more than $200 \mathrm{~mm}$ thick aluminum alloy die rolling plates. Nowadays, in China it is difficult to produce high-strength aluminum alloy hot-rolled plate with a thickness over $200 \mathrm{~mm}$. However, the thickness of the 7075 hot-rolled aluminum alloy was greatly limited due to the inherent property of the rolling process.

Many mold materials had higher requirements on the material thickness according to the requirements of products. The key problem was how to obtain high thermal conductivity, high strength, and good wear resistance of thick plate aluminum alloy materials, so it can meet the requirement of plastic polymer processing die. It was found that only the parting surface required high strength, while the auxiliary part primarily played a part of supporting. In the meanwhile, the parting surface and the auxiliary part must be an integral material. In consequence, bimetallic cladding materials were considered to fabricate mold material for prototype, production, and blow molding applications. So it was conducive to solve problems of thickness limitation to some extent.

The manufacturing technologies of bimetallic cladding materials included explosive welding [5], roll-bonding [6], and diffusion bonding [7]. However, these technologies had problems such as low bonding strength, high cost, and low efficiency. Solid-liquid compound casting [8-11] was a common compound casting of $\mathrm{Al}-\mathrm{M}(\mathrm{M}$, metal), but it need to wipe off oxide film on the surface of the matrix, and the production process was relatively complex. Consequently, researchers had developed a novel compound casting, namely, the impact jet solid-liquid compound casting, with no need to process the matrix. During the impact jet solidliquid compound casting, molten metal was poured on the matrix's surface at a certain angle and speed so that impact convection heat transfer between molten metal and matrix was applied to remove oxidation film on the matrix's surface. Then, it realized metallurgical bonding. Retrogression and reaging (RRA) treatment was commonly employed to improve microstructure, mechanical properties [12-14], resistance to stress corrosion cracking [15-17], and resistance to fatigue crack propagation [18-20] of 7XXX series aluminum alloy.

Based on the above considerations, the authors adopted a novel compound casting, namely, the impact jet solid-liquid compound casting, to fabricate the 3A21/7075 aluminum cladding material. The influence of RRA treatment on the microstructure and hardness of the 3A21/7075 aluminum alloy cladding material was investigated in details. We hope that this research work will provide theoretical and experimental data support for the 7075 aluminum alloy applied as a mold material for prototype, production, and blow molding applications.

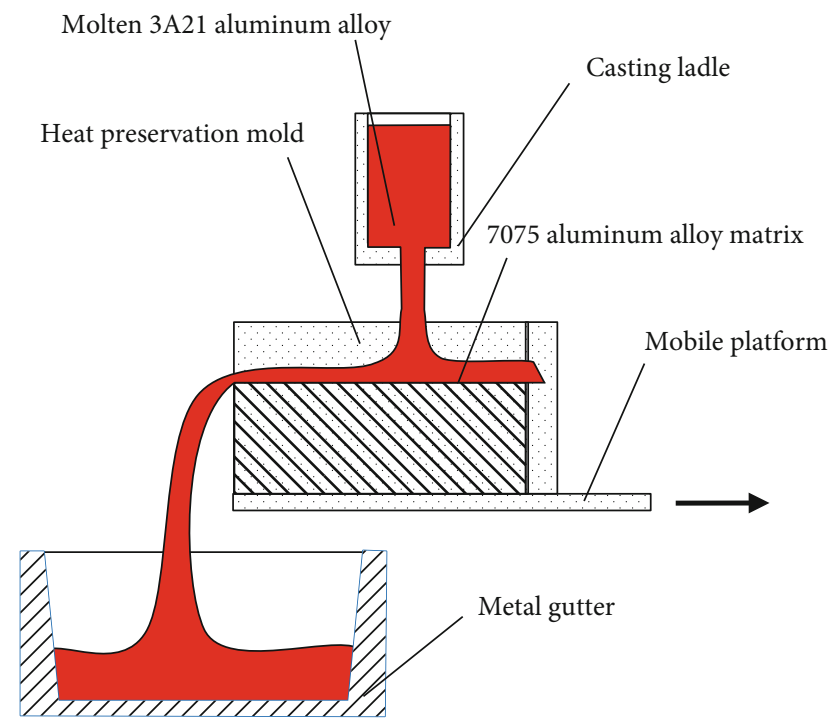

Figure 1: Process diagram of the impact jet solid-liquid compound casting.

TABLE 2: Process parameters of RRA.

\begin{tabular}{llcc}
\hline Preaging & Retrogression & Cooling mode & Reaging \\
\hline $120^{\circ} \mathrm{C} \times 12 \mathrm{~h}$ & $350^{\circ} \mathrm{C} \times 120 \mathrm{~s}$ & Water-cooling & $120^{\circ} \mathrm{C} \times 12 \mathrm{~h}$ \\
\hline
\end{tabular}

\section{Materials and Methods}

The commercial 7075-T651 aluminum alloy hot-rolled plates in the T651 condition were utilized as the matrix material (abbreviated as the 7075-T651MM). The molten 3A21 aluminum alloy was chosen as the impact jet solidliquid compound casting material (abbreviated as the $3 \mathrm{~A} 21 \mathrm{CCM})$. The chemical composition was shown in Table 1. The impact jet solid-liquid compound casting technology was chosen to fabricate the 3A21/7075 cladding material. The process diagram of the impact jet solid-liquid compound casting is shown in Figure 1. The experiment was divided into two stages: one was the formation of oxide film breaking and melting layer, and the other was the formation of coating layer. In the first stage, the oxide film on the surface of the substrate was removed by using the enhanced heat transfer effect and impact force of the liquid metal impinging jet. Firstly, the high-temperature cladding liquid metal was poured onto the surface of the metal substrate below. The impinging jet of the liquid metal strengthens the heat transfer and quickly heats and melts the surface of the substrate. The oxide film on the surface 

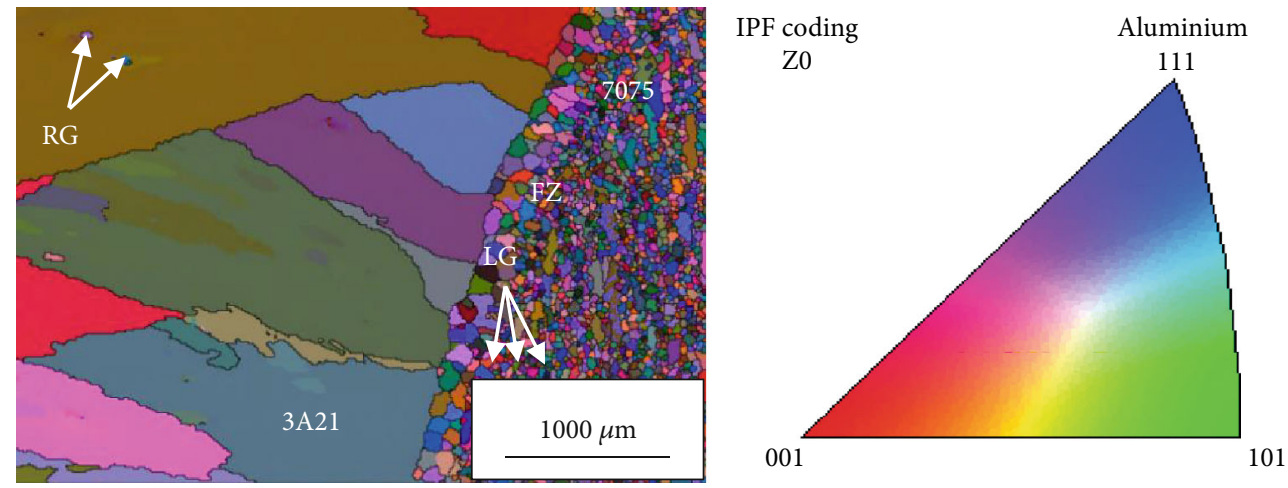

FIgURE 2: Evolution of grain morphology and size of the 3A21/7075 cladding material.

of the substrate was easily broken and carried away by the impact force of the liquid metal flow due to the loss of solid support. The substrate moves horizontally at a certain speed under the liquid flow, and the oxide film on the surface will be destroyed when removed. In the second stage, a large amount of heat was still transferred to the substrate during the formation of the thicker coating. In order to reduce the heat input during the formation of the coating, another ladle was used to pour the low-temperature molten metal at this stage. The melted base metal was mixed with the molten metal of the coating and finally solidified with the unmelted base metal. The 7075 aluminum matrix was placed on the mobile platform and fixed with a clamping mechanism. The motor was adopted to adjust the mobile speed of the 7075 aluminum matrix and the distance between the casting ladle and the 7075 aluminum matrix. At the initial stage of the impact jet solid-liquid compound casting, the molten $3 \mathrm{~A} 21$ aluminum alloy was evenly poured from one end of the 7075 matrix to the other end. The movement time of the 7075 aluminum alloy matrix was delayed to achieve the effect of preheating so the $3 \mathrm{~A} 21 /$ the 7075 cladding material could be well combined with each other. In the middle stage of the impact jet solid-liquid compound casting, heat and power of the 3A21 aluminum alloy during the casting process were utilized to break through the oxidation film on the surface of the 7075 matrix. When the 7075 matrix moved to the tail end at a speed of $15 \mathrm{~mm} / \mathrm{s}$, that is, at the end of the impact jet solid-liquid compound casting, a melting layer was formed on the surface of the 7075 matrix. Finally, a metallurgical bonding between the $3 \mathrm{~A} 21$ alloy and the 7075 matrix was formed. On the preliminary experiments, the optimized RRA treatment was carried out on the $3 \mathrm{~A} 21 / 7075$ cladding material and the process parameters of RRA treatment was shown in Table 2.

The electron backscattered diffraction (EBSD) technique was utilized to analyze the microstructure of the 3A21/7075 cladding material. The Tecnai G2-F30 transmission electron microscope (TEM) with an energy dispersive spectrometer (EDS) was employed to investigate phases of the 3A21/7075 cladding material. A microhardness tester with a load of $0.49 \mathrm{~N}$ and holding time of $10 \mathrm{~s}$ was applied to examine microhardness distribution of the 3A21/7075 cladding material.
TABLE 3: Fraction of three kinds of grains (\%).

\begin{tabular}{lcc}
\hline Substructured grains & Recrystallized grains & Lengthened grains \\
\hline 70.83 & 24.76 & 4.41 \\
\hline
\end{tabular}

\section{Results and Discussion}

Figure 2 contains the evolution of morphology and size of grains in the interface area of the 3A21/7075 cladding material. The grain distribution was represented with different colors in Figure 2. The interface in the fusion zone (FZ) between the 7075-T651MM and the 3A21CCM was distinct. On both sides of the fusion zone, that is, in different regions of the matrix and the casting layer, the shape and size of the particles were obviously different. There were a large number of equiaxed grains (grain aspect ratio close to 1 within the visual field) and several lengthened grains (LG) in the $3 \mathrm{~A} 21 \mathrm{CCM}$ casting zone. It was the reason for the anomalous growth grains of the 3A21 alloy in the casting layer which had a grain boundary movement and grain rearrangement process during the heat treatment process (RRA process). When metal and alloy were heated at high temperatures, they had a spontaneous tendency to move through grain boundary to reduce the total grain boundary area and thus reduced the total grain boundary energy. During the RRA process, some grains usually swallowed up other surrounding grains in appropriate grain boundary orientation through migration of grain boundary to form some different grains from equiaxed grains. There appeared coarsened fibrous grains (grain aspect ratio ranging from 2 to 5 within the visual field), along with some recrystallized grains precipitated in fibrous grains in the 7075-T651MM region. The fraction is given in Table 3. Three different kinds of grains included substructured grains (including equiaxed grains and fibrous grains), recrystallized grains, and lengthened grains, which were detected by statistics of the EBSD system. In general, grain boundaries were divided into three types according to their orientation angles, which were low-angle grain boundaries (LAGBs, $2^{\circ} \leq \theta \leq 5^{\circ}$ ), high-angle grain boundaries (HAGBs, $\theta \geq 15^{\circ}$ ), and medium-grain boundaries (MAGBs, $5^{\circ}<\theta<15^{\circ}$ ) $[21,22]$. The fraction of the three kinds of grains was $70.83 \%, 24.76 \%$, and $4.41 \%$. 


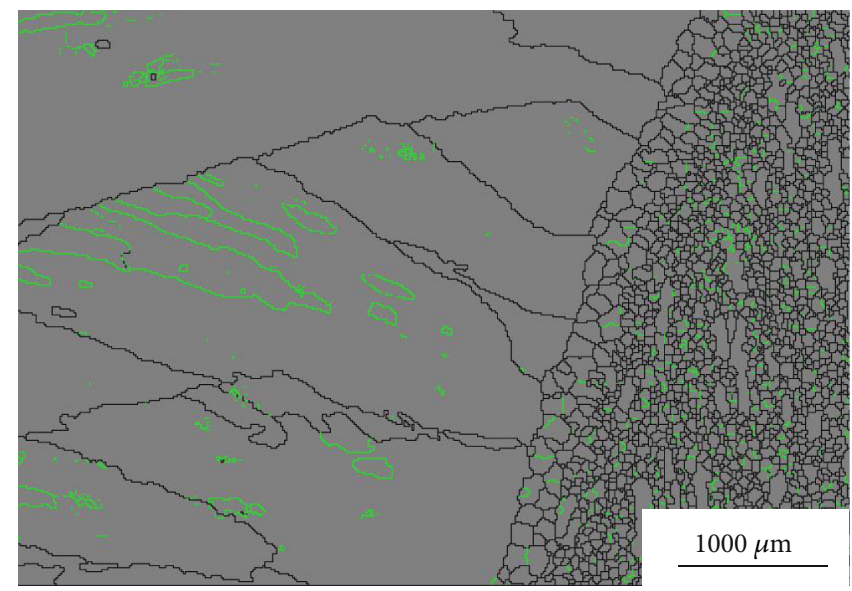

FIGURE 3: The grain boundary diagram of the 3A21/7075 cladding material.

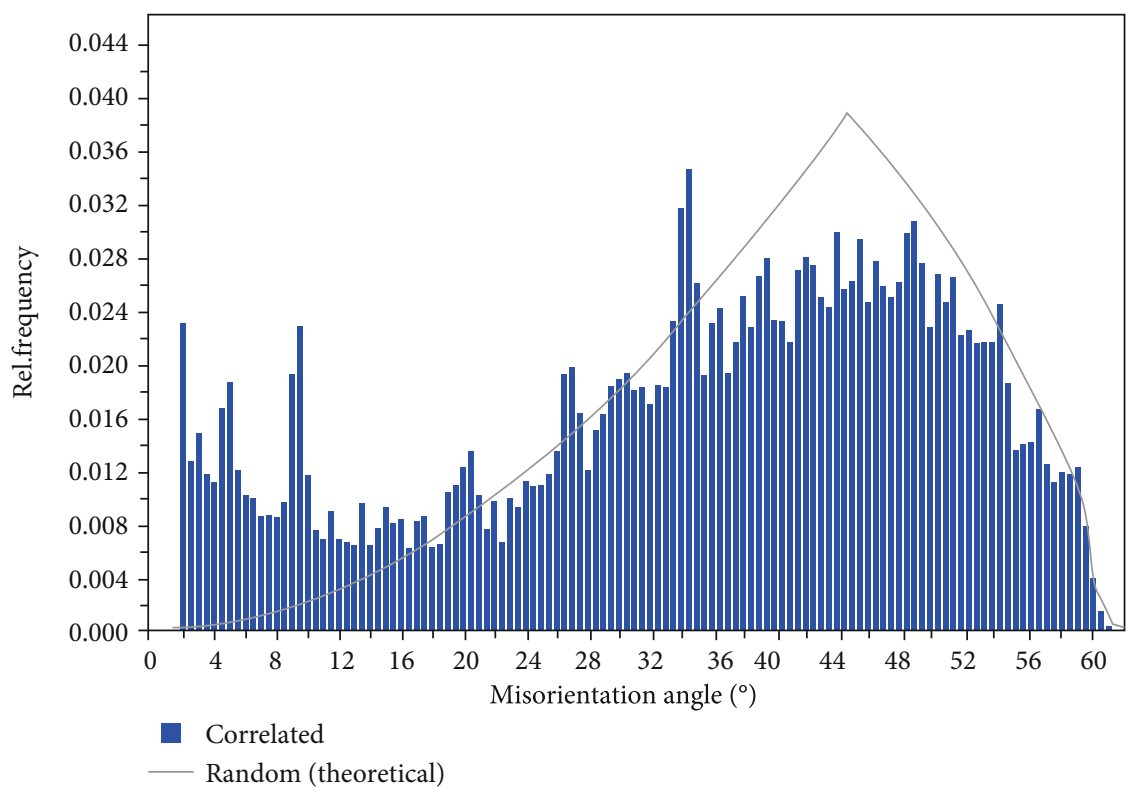

FIgURE 4: Misorientation angle of grains of the 3A21/7075 cladding material.

For polycrystalline materials, the misorientation angle distribution of grain boundaries had an important influence on the mechanical properties of the materials. Figure 3 presents the grain boundary diagram of the 3A21/7075 cladding material, in which the blue, red, and green lines represented HAGBs, LAGBs, and MAGBs, respectively. However, the magnitude of grain boundary energy was a function of the degree of misorientation, being larger for high-angle boundaries. Grain boundaries had more chemically reactive than the grains as a consequence of this boundary energy. Moreover, impurity atoms are preferentially segregated along the grain boundaries because of their higher energy state. While brittle cracks that expanded along HAGBs need to consume more energy, that is, HAGBs could effectively obstruct the intergranular expansion of cracks. It can be seen from the analysis in Figure 3 that MAGBs with different densities distributed both the internal and boundary of the 7075 matrix grain, so it had relatively lower grain boundary energy. The intergranular crack propagation ability can be reduced by reducing the particle boundary energy to some extent.

Figure 4 displays the misorientation angle distribution of grains of the 3A21/7075 cladding material. "Uncorrelated" meant misorientations calculated from random points in the scan (blue bar). "Random" showed the random distribution of misorientations for a purely random texture (black line). It can be observed from Figure 4 that the misorientation angle distribution of uncorrelated grains was basically consistent with the random curve. Then, it can be observed as a random distribution of grain orientation. However, a little deviation can be found between the uncorrected and the random curve from Figure 4. A conclusion can be drawn that a little rolling deformation texture existed on the side of the 7075 aluminum alloy. For aluminum alloy with a thick plate structure, many factors would affect its properties, including recrystallization structure, residual second phase, aging precipitated phase, and texture. The texture orientation 


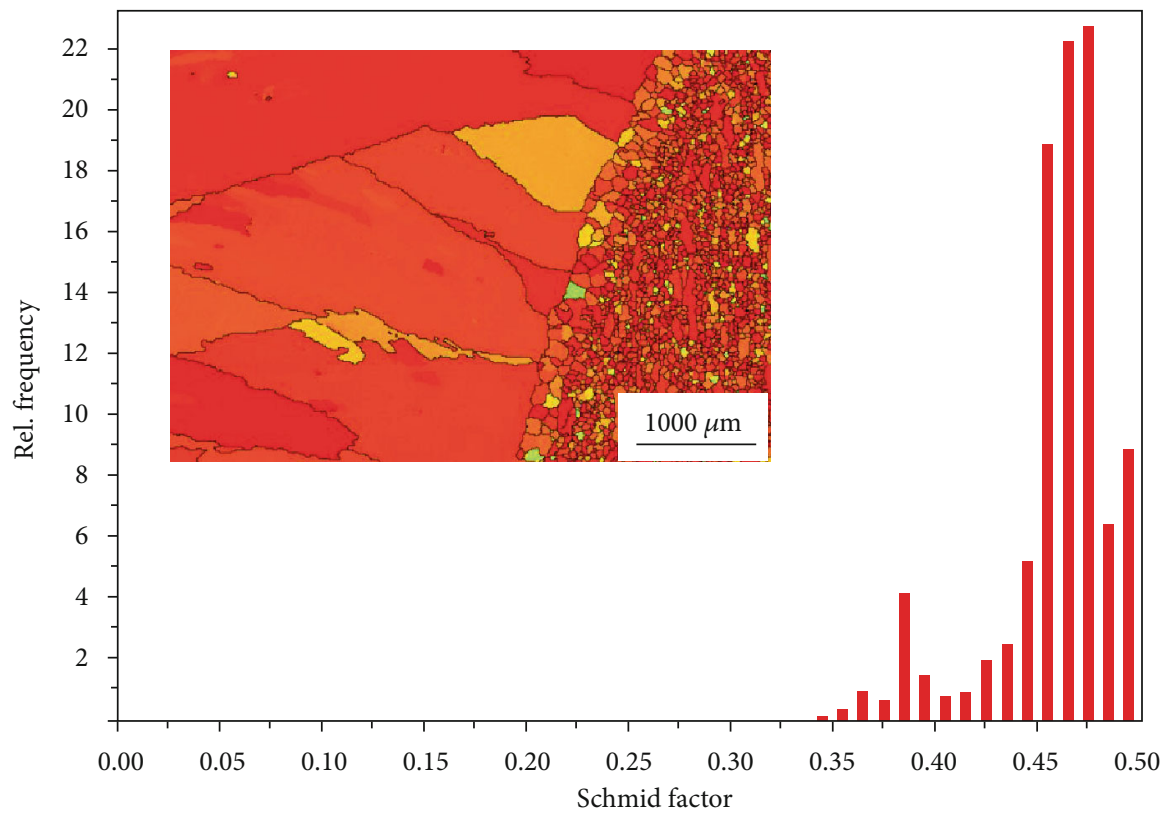

FIGURE 5: The Schmid factor distribution of grains in each zone of the 3A21/7075 cladding material.

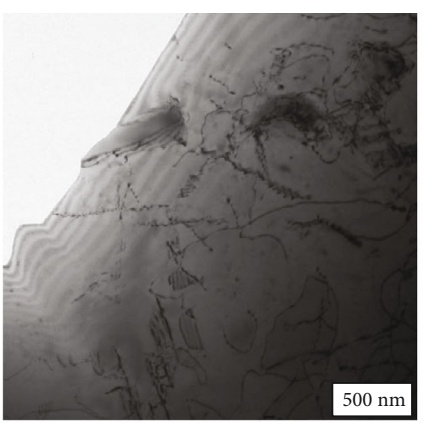

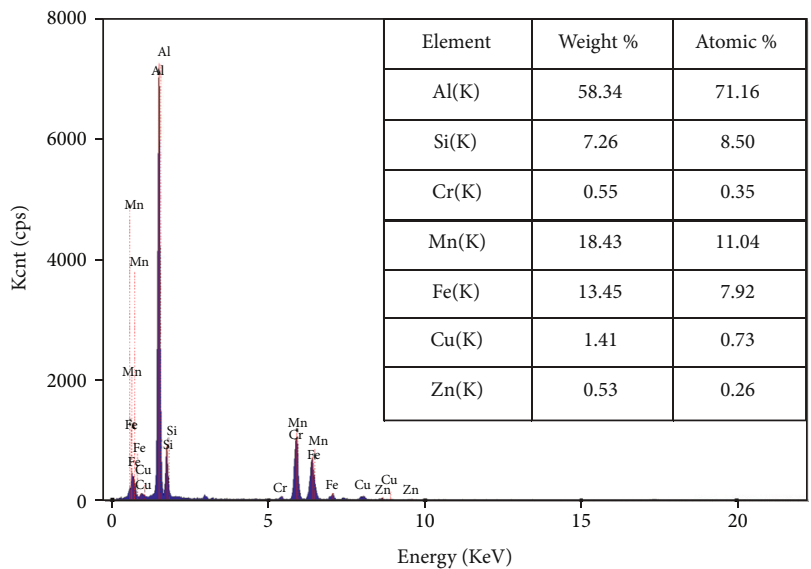

(a) Bulk phase

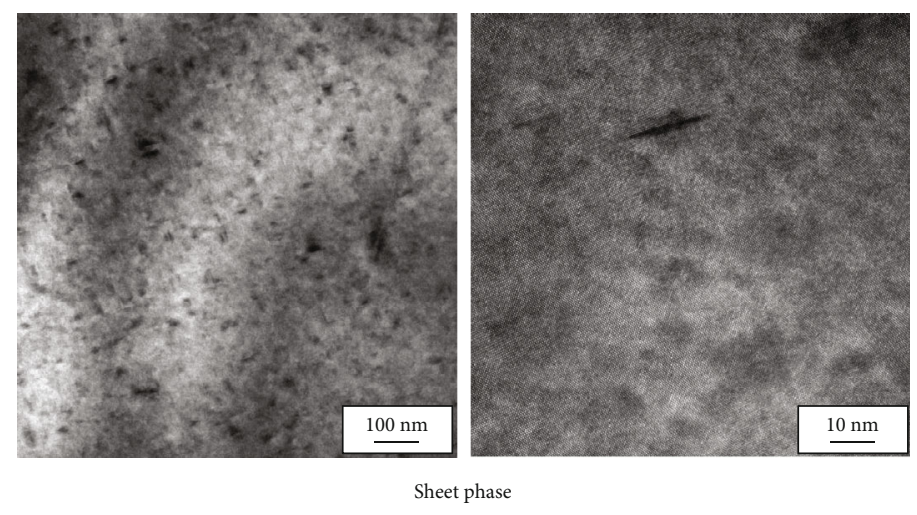

(b) Sheet phase

FIGURE 6: TEM photos of the 3A21 cladding layer and EDS result.

of the interfacial layer had an important effect on the grain growth, uniform grain distribution, mechanical properties, and corrosion resistance of the interfacial layer.

Figure 5 describes the grain Schmid factor distribution of the 3A21/7075 cladding material. As being seen from Figure 5, significant differences were displayed between the
3A21 alloy zone and the 7075 matrix zone. The high Schmid factor was located at the 7075 matrix zone. The Schmid factor distribution of the $3 \mathrm{~A} 21 / 7075$ cladding material ranged from 0.3 to 0.5 . The average value of the Schmid factor was 0.46 . The larger value of the Schmid factor was, the larger the resolved shear force was. The high Schmid factor zone of $m$ 


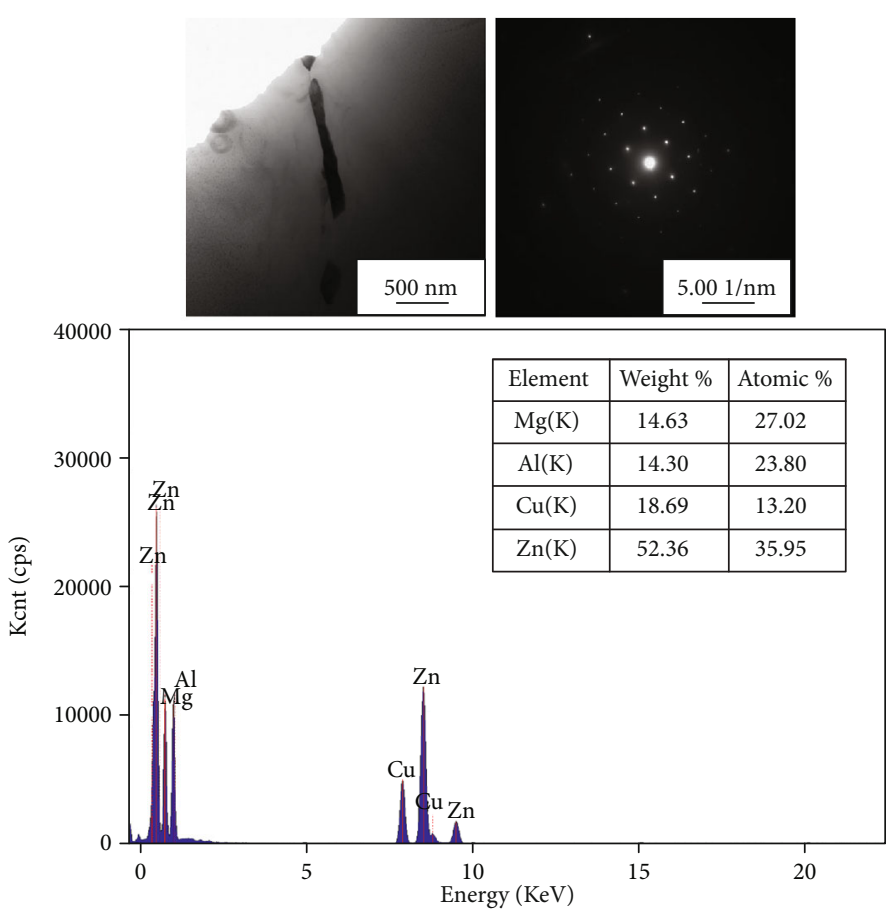

(a) Strip phases

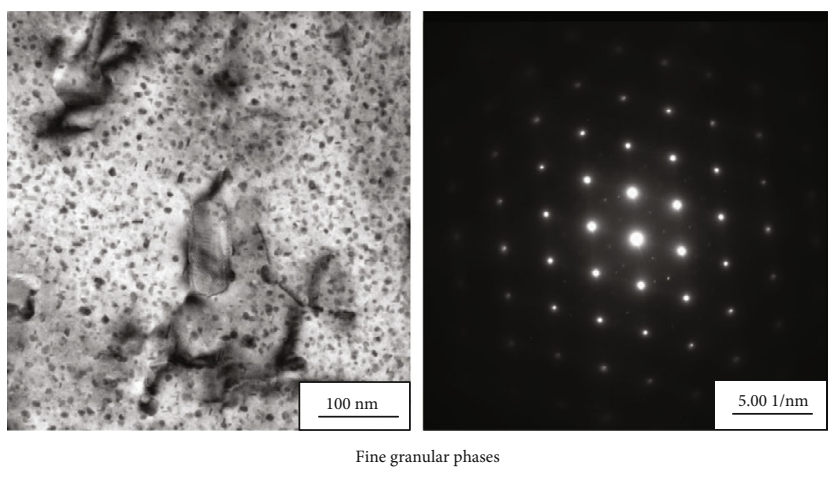

(b) Fine granular phases

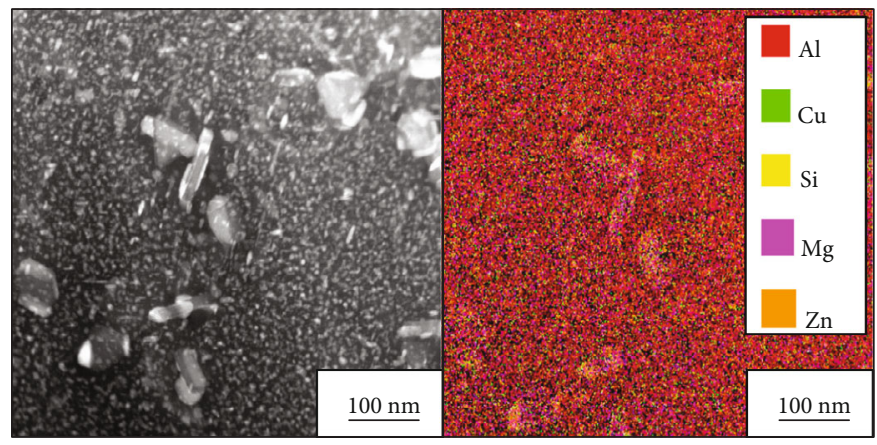

Coarsened granular phases and HAADF

(c) Coarsened granular phases and HAADF

FIGURE 7: TEM photos of the 7075 matrix.

$\geq 0.45$ was defined as a "soft" orientation zone in terms of the resolved shear stress, which was higher in "soft" zone than in the rest zones under the same applied stress [23, 24]. It contributed to grain boundary migration and grain rotation under external force [25]. The larger value of the Schmid factor indicated better deformability of the 3A21/7075 cladding material.

Figure 6 indicates a TEM photo of the 3A21 cladding layer. Two different kinds of phases included a bulk phase and some sheet phase. The bulk phase was irregular in shape (Figure 6(a)). It was calculated from EDS result that the ratio of $\mathrm{Al}:(\mathrm{Fe}, \mathrm{Mn}): \mathrm{Si}$ was nearly $9: 3: 1$. The bulk phase was identified as Al9Fe0.84Mn2.1Si by XRD analysis according to PDF42-1206\# card [26]. The 3A21 aluminum alloy belongs to the heat treatment cannot be strengthened aluminum alloy, so a small amount of second phase has little effect on the microstructure and properties of the 3A21 aluminum alloy. Some sheet phases were undetermined and fine with a length of $10 \mathrm{~nm}$ and a width of less than $1 \mathrm{~nm}$; then, the tip position tended to cause stress concentration.

Figure 7 provides TEM photos of the 7075 matrix. There appeared three kinds of phases, namely, coarsened strip phase precipitated at the grain boundary, some coarsened granular phases, and amounts of fine granular phases in the internal of the grain. The strip phase was a little coarse and rich in $\mathrm{Al}, \mathrm{Zn}, \mathrm{Mg}$, and $\mathrm{Cu}$ from the result of EDS (Figure 7(a)), which was inferred as T phase (AlCuMgZn). Vast fine granular phases were in the internal of the grain (Figure 7(b)). Fine granular phases were regarded as newly precipitated $\eta^{\prime}\left(\mathrm{MgZn}_{2}\right)$ after RRA treatment, while some coarsened granular phases were judged as unmelted $\eta^{\prime}$ $\left(\mathrm{MgZn}_{2}\right)$ from Figure $7(\mathrm{c})$. The coarsened granular phases and HAADF image were given. The main elements included $\mathrm{Al}, \mathrm{Cu}, \mathrm{Si}, \mathrm{Mg}$, and $\mathrm{Zn}$. They were consistent with designed material. It is worth noting that these fine and dispersed $\eta^{\prime}$ $\left(\mathrm{MgZn}_{2}\right)$ were beneficial to improve comprehensive 


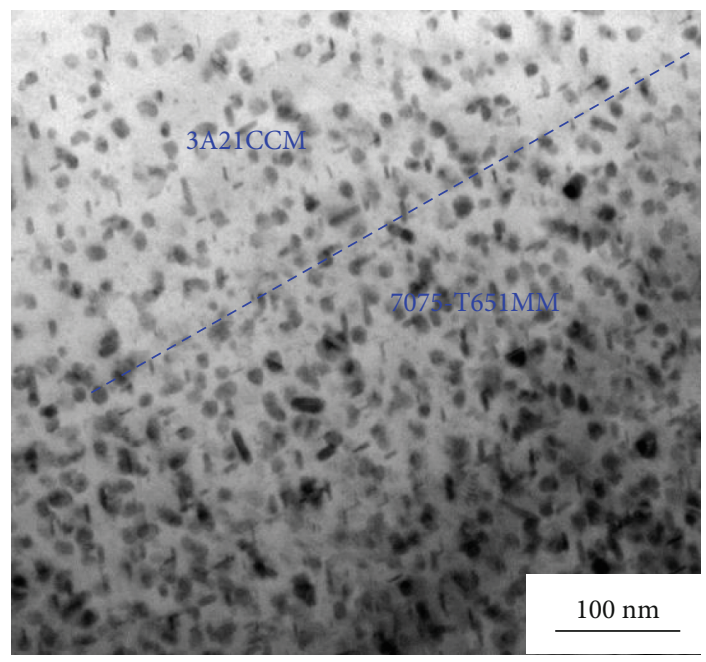

FIgURE 8: TEM photo of the fusion zone.

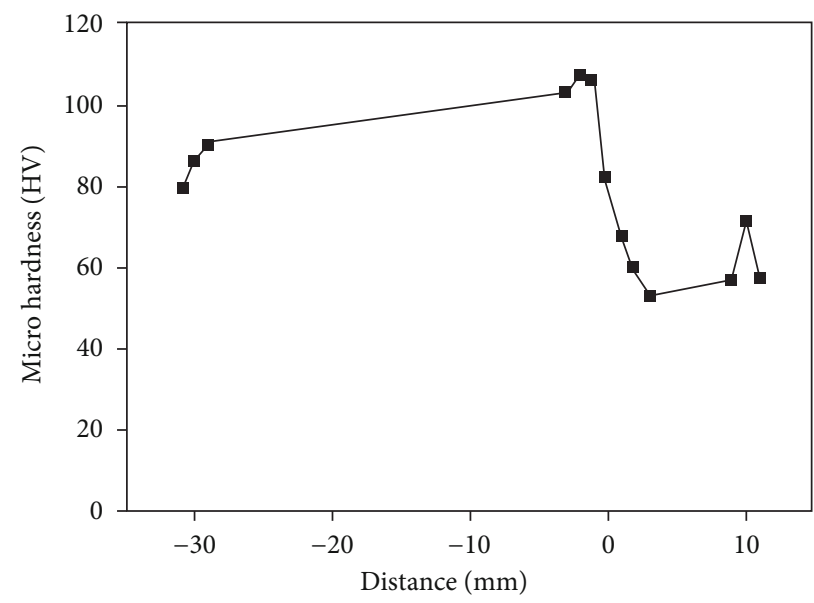

Figure 9: Microhardness test result of the 3A21/7075 aluminum alloy cladding material.

mechanical properties and corrosion resistance of 7055 aluminum alloy. The generally accepted precipitation sequences for 7XXX series alloys were as follows: supersaturated solid solution(SSS) $\longrightarrow$ coherent stable GP zones $\longrightarrow$ semicoherent intermediate $\eta^{\prime}\left(\mathrm{MgZn}_{2}\right) \longrightarrow$ incoherent stable $\eta\left(\mathrm{MgZn}_{2}\right)$ or $\mathrm{T}(\mathrm{AlZnMgCu})$. The morphology size and the degree of coherence with the matrix would influence the property of aluminum alloy.

Figure 8 illustrates TEM photos of the fusion zone between the matrix and casting materials. They appeared heterogeneous, fine granular phases, and sheet phases in Figure 8. It brought into correspondence with Figures 6(b) and $7(\mathrm{~b})$, respectively. This zone separately and uniquely had two kinds of phases that belonged to the 3A21 cladding layer and the 7075 matrix, so this zone was the fusion zone.

Figure 9 depicts the microhardness test result of the $3 \mathrm{~A} 21 / 7075$ cladding material. The 3A21/7075 cladding material showed a degree of softening. It could be found from the EBSD and TEM results that plenty of fine phases precipitated in the inner region of the grains of the $3 \mathrm{~A} 21 / 7075$. At the same time, all fine-precipitated phases grew up to some extent. Finally, grain growth was the dominant factor, which was responsible for the softening phenomenon.

\section{Conclusion}

The 3A21/7075 aluminum alloy cladding material with good quality was successfully prepared by the impact jet solidliquid compound casting method on self-developed composite equipment. The interface between cladding alloy (the 3A21) and matrix alloy (the 7075) was metallurgical bonding. Three different kinds of grains included substructured grains (including equiaxed grains and fibrous grains), recrystallized grains, and lengthened grains, which were detected by statistics of EBSD system. The fraction of three kinds of grains was $70.83 \%, 24.76 \%$, and $4.41 \%$. Regression reaging treatment (RRA) has a significant effect on the microstructure and properties of the 3A21/7075 aluminum alloy cladding material. After RRA treatment, the matrix, which was the 7075-T651MM, had better deformability. Both sides of 
the $3 \mathrm{~A} 21$ and the 7075 precipitated amount of fine phases in grains helped to improve comprehensive mechanical properties of the 3A21/7075 aluminum alloy cladding material. The microhardness of the transition region of the 3A21/7075 clad aluminum alloy shows an obvious gradient distribution. However, grains of the 3A21/7075 aluminum alloy cladding material grew up and caused a decrease in hardness. Therefore, the next work was to further optimize RRA treatment in order to obtain fine and dispersed phases with no grain overgrowing.

\section{Data Availability}

The data used to support the findings of this study are included within the article.

\section{Conflicts of Interest}

The authors declare that there is no conflict of interest.

\section{Acknowledgments}

The research was funded by the Natural Science Fund of China (grant number 51671096), Materials Science and Engineering Discipline Team of Jiamusi University (grant number JDXKTD-2019001), Collaborative Innovation Program of Jiamusi University (grant number 2011xtcx201603), Natural Science Foundation of Heilongjiang Province (E2015038), and Scientific Research Fund of Heilongjiang Education Department Project (2016-KYYWF-0556, 2017KYYWF-0582, 2019-KYYWF-1373, 2019-KYYWF-1375).

\section{References}

[1] J. Kim, R. Smierciak, Y. S. Shin, and L. Cooper, "Advances in aluminum mold block for plastic injection molding operations," in Proceedings of the 13th International Conference on Aluminum Alloys, pp. 1621-1627, Pittsburgh, USA, 2012.

[2] H. Aarabi and M. Alizadeh, "Improvement of microstructure and corrosion properties of AA7075 Al alloy by melt shearing process," Materials Letters, vol. 275, article 128085, 2020.

[3] X. Cui, X. Xu, Y. Ning, and Y. Zhao, "Microstructure and Mechanical Properties of 7075 Al Alloy Processed by Combined Cold-rolling and T6 Heat-treatment," Materials Review, vol. 31, no. 7, pp. 88-91, 2017.

[4] Z. Tao, W. Yunxin, G. Hai, S. Wenze, J. Fangmin, and J. Shaosong, "Analysis of temperature asymmetry of aluminum alloy thick plate during snake hot rolling," The International Journal of Advanced Manufacturing Technology, vol. 87, no. 1-4, pp. 941-948, 2016.

[5] T. Zhang, W. Wang, W. Zhang et al., "Microstructure evolution and mechanical properties of an AA6061/AZ31B alloy plate fabricated by explosive welding," Journal of Alloys and Compounds, vol. 735, pp. 1759-1768, 2018.

[6] Z. J. Wang, M. Ma, Z. X. Qiu, J. X. Zhang, and W. C. Liu, "Microstructure, texture and mechanical properties of AA 1060 aluminum alloy processed by cryogenic accumulative roll bonding," Materials Characterization, vol. 139, pp. 269-278, 2018.

[7] H. Zhang, J. L. Li, C. S. Wang, J. T. Xiong, and F. S. Zhang, "Equal-strength precision diffusion bonding of AA6063 alu- minum alloy with the surface passivated by a self-assembled monolayer," International Journal of Materials Research, vol. 108, no. 7, pp. 571-577, 2017.

[8] J. Feng, B. Ye, L. Zuo et al., "Bonding of aluminum alloys in compound casting," Metallurgical and Materials Transactions A, vol. 48, no. 10, pp. 4632-4644, 2017.

[9] R. Mola, T. Bucki, and M. Gwoździk, "The effect of a zinc interlayer on the microstructure and mechanical properties of a magnesium alloy (AZ31)-aluminum alloy (6060) joint produced by liquid-solid compound casting," The Journal of The Minerals, Metals \& Materials Society, vol. 71, no. 6, pp. 2078-2086, 2019.

[10] J. Shin, T. Kim, K. Lim et al., "Effects of steel type and sandblasting pretreatment on the solid-liquid compound casting characteristics of zinc-coated steel/aluminum bimetals," Journal of Alloys and Compounds, vol. 778, pp. 170-185, 2019.

[11] G. Y. Li, W. M. Jiang, F. Guan, J. Zhu, H. Jiang, and Z. Fan, "Effect of insert materials on microstructure and mechanical properties of $\mathrm{Al} / \mathrm{Mg}$ bimetal produced by a novel solid-liquid compound process," Journal of Manufacturing Processes, vol. 47, pp. 62-73, 2019.

[12] A. Zieliński, J. Chrzanowski, M. Warmuzek, A. Gazda, and E. Jezierska, "Influence of retrogression and reaging on microstructure, mechanical properties and susceptibility to stress corrosion cracking of an Al-Zn-Mg alloy," Materials and Corrosion, vol. 55, no. 2, pp. 77-87, 2004.

[13] H. T. Naeem, K. S. Mohammed, R. A. Khairel, and A. Rahmat, "The role of direct chilling, retrogression and reaging treatment on mechanical properties of high strength aluminum alloy," Advanced Materials Research, vol. 795, pp. 211-218, 2013.

[14] G. Ozer and A. Karaaslan, "Properties of AA7075 aluminum alloy in aging and retrogression and reaging process," Transactions of Nonferrous Metals Society of China, vol. 27, no. 11, pp. 2357-2362, 2017.

[15] M. Baydogan, H. Cimenoglu, E. Sabri Kayali, and J. Rasty, "Improved resistance to stress-corrosion-cracking failures via optimized retrogression and reaging of 7075-T6 aluminum sheets," Metallurgical and Materials Transactions A, vol. 39, no. 10, pp. 2470-2476, 2008.

[16] Y. Reda, R. Abdel-Karim, and I. Elmahallawi, "Improvements in mechanical and stress corrosion cracking properties in Alalloy 7075 via retrogression and reaging," Materials Science and Engineering A, vol. 485, no. 1-2, pp. 468-475, 2008.

[17] Y. P. Xiao, Q. L. Pan, W. B. Li, X. Y. Liu, and Y. B. He, "Influence of retrogression and re-aging treatment on corrosion behaviour of an $\mathrm{Al}-\mathrm{Zn}-\mathrm{Mg}-\mathrm{Cu}$ alloy," Materials and Design, vol. 32, no. 4, pp. 2149-2156, 2011.

[18] X. Chen, Z. Y. Liu, M. Lin, A. Ning, and S. Zeng, "Enhanced fatigue crack propagation resistance in an $\mathrm{Al}-\mathrm{Zn}-\mathrm{Mg}-\mathrm{Cu}$ alloy by retrogression and reaging treatment," Journal of Materials Engineering and Performance, vol. 21, no. 11, pp. 2345-2353, 2012.

[19] Y. L. Wang, Q. L. Pan, L. L. Wei, B. Li, and Y. Wang, "Effect of retrogression and reaging treatment on the microstructure and fatigue crack growth behavior of 7050 aluminum alloy thick plate," Materials and Design, vol. 55, pp. 857-863, 2014.

[20] Y. Wang, Y. L. Deng, S. D. Liu, Z. Shan, J. Tang, and X. Zhang, "Effect of RRA treatment on the microstructure and fatigue behavior of 7020 aluminum alloy," in High Performance Structural Materials, pp. 349-359, 2018. 
[21] J. H. Park, K. Hamad, I. P. Widiantara, and Y. G. Ko, "Strain and crystallographic texture evaluation of interstitial free steel cold deformed by differential speed rolling," Materials Letters, vol. 147, pp. 38-41, 2015.

[22] Z. F. Yan, D. H. Wang, X. L. He et al., "Deformation behaviors and cyclic strength assessment of AZ31B magnesium alloy based on steady ratcheting effect," Materials Science \& Engineering A, vol. 723, pp. 212-220, 2018.

[23] C. D. Barrie, A. P. Boyle, S. F. Cox, and D. J. Prior, "Slip systems and critical resolved shear stress in pyrite: an electron backscatter diffraction (EBSD) investigation," Mineralogical Magazine, vol. 72, no. 6, pp. 1181-1199, 2008.

[24] X. Chao, S. Qiaoyan, X. Lin, and S. Jun, "Schmid factor maps for predicting slip and twinning behaviors in zirconium," Rare Metal Materials and Engineering, vol. 48, no. 8, pp. 2400-2405, 2019.

[25] Z. G. Liu, P. J. Li, L. T. Xiong, T. Liu, and L. He, "High-temperature tensile deformation behavior and microstructure evolution of Ti55 titanium alloy," Materials Science \& Engineering A, vol. 680, pp. 259-269, 2017.

[26] R. A. Brand, G. Le Caër, J. M. Dubois, F. Hippert, C. Sauer, and J. Pannetier, "The magnetic transition in Fe-substituted hexagonal $\beta$-Al9SiMn3," Journal of Physics: Condensed Matter, vol. 2, pp. 3855-3866, 1990. 